\title{
ENSINAR HISTÓRIA NOS ANOS INICIAIS DO ENSINO FUNDAMENTAL: DESAFIOS CONCEITUAIS E METODOLÓGICOS
}

\section{TEACHING HISTORY IN THE EARLY YEARS OF ELEMENTARY SCHOOL: CONCEPTUAL CHALLENGES AND METHODOLOCAL}

\author{
Patrícia Karla Soares Santos Dorotéio ${ }^{1}$
}

\begin{abstract}
RESUMO: O presente artigo propõe-se a levantar questões relevantes em relação ao ensino de História nos Anos Iniciais do Ensino Fundamental. Em linhas gerais, busca traçar elementos que evidenciem as especificidades do saber histórico no contexto dessa fase de escolaridade. Em consonância, faz um breve panorama sobre o currículo que tem se efetivado em sala de aula, junto às considerações acerca do professor pedagogo em atuação com a disciplina História. Nas referências teórico-metodológicas que orientam o ensino de História hodierno percebe-se uma carência de estudos, principalmente no que se refere à relação com a historiografia contemporânea na prática pedagógica dos professores que iniciam os alunos no saber histórico escolar. Para a tessitura do artigo, foram analisados questionários aplicados aos docentes dos Anos Iniciais do Ensino Fundamental, em exercício em escolas da Região Metropolitana de Belo Horizonte. Os achados da pesquisa corroboram com estudos recentes sobre o ensino da disciplina nos Anos Iniciais, nos quais se destacam algumas mudanças e permanências que endossam os desafios colocados ao ensino de História nessa fase de escolarização: avanços metodológicos e historiográficos no saber de referência; professor pedagogo, sem formação específica na área da História; reprodução de concepções; manutenção de metodologias, conteúdos e conceitos tradicionalmente empregados no ensino de História; público infantil, com as especificidades do ser criança.
\end{abstract}

Palavras-chave: Ensino de História. Práticas Pedagógicas. Metodologia do ensino de História. Anos Iniciais do Ensino Fundamental.

1 Mestre em Educação pela PUC Minas. Professora do Departamento de Educação e Ciências Humanas da Universidade do Estado de Minas Gerais, unidade Ibirité. 


\begin{abstract}
This article aims to present relevant issues in relation to the history teaching for children in elementary school. In general, seeks to present the specifics of historical knowledge in the context of this stage of formation. Thus, it makes a brief summary of the curriculum that has been implemented in the classroom, along with consideration of the performance of pedagogue teacher with the history teaching. In the theoretical-methodological references that guide the teaching of history today, one sees a lack of studies, particularly as regards the relationship with contemporary historiography in the pedagogical practice of teachers to initiate students in historical knowledge. For the construction of the article, questionnaires were analyzed that were applied to teachers in the early years of elementary school, and working in the metropolitan region of Belo Horizonte. The results corroborate recent studies on the subject of education for children, which highlights some changes and continuities that endorse the challenges to the teaching of history in this school phase: methodological and historiographical advances in reference knowledge; teachers without specific training in history; reproduction of old conceptions; maintenance methods, content and concepts traditionally used in teaching history; child audience with the specifics of being a child.
\end{abstract}

Keywords: History teaching. Pedagogical practices. Methodology of teaching history. Early years of elementary school. 


\section{Introdução}

O presente artigo propõe-se a levantar questões relevantes em relação ao ensino de História nos Anos Iniciais do Ensino Fundamental. Em linhas gerais, busca traçar elementos que evidenciem as especificidades do saber histórico no contexto dessa fase de escolaridade. Em consonância, faz um breve panorama sobre o currículo que tem se efetivado em sala de aula, junto às considerações acerca do professor pedagogo em atuação com a disciplina História.

O artigo dialoga com a pesquisa "Ensino de História nos Anos Iniciais, conteúdos, métodos e concepções", desenvolvida pela autora ao longo dos anos 2014 e 2015, na qual, por meio de trinta e três questionários aplicados a professores de $1^{\circ}$ a $5^{\circ}$ ano do Ensino Fundamental, da região metropolitana de Belo Horizonte, buscou-se evidenciar quais elementos teóricos e metodológicos do saber histórico estavam presentes, ou mostravam-se com mais ênfase, no currículo em prática nos Anos Iniciais do Ensino Fundamental.

Nas referências teórico-metodológicas que orientam o ensino de História hodierno percebe-se uma variedade de estudos - que produzem reflexões sobre as concepções, métodos, práticas e materiais pedagógicos - relacionados aos Anos Finais do Ensino Fundamental, momento em que a disciplina deve ser ministrada pelo professor licenciado em História. Em relação aos Anos Iniciais, indicam a carência de estudos relativos a essa fase de escolarização, principalmente no que se refere à relação com a historiografia contemporânea na prática pedagógica dos professores que iniciam os alunos no saber histórico escolar. (CODANI, 2000; SILVA, 2013). Nessa perspectiva, entende-se a relevância deste trabalho.

Propor uma reflexão acerca do saber histórico nos Anos Iniciais do ensino Fundamental demanda uma breve consideração acerca dos caminhos teóricos e metodológicos percorridos pela História nas últimas décadas. Nesse ponto, não cabe uma defesa ingênua de que o saber escolar seja apenas uma transposição da ciência de referência, ao tratar da História devem-se considerar as inúmeras influências, para além do saber acadêmico, que rodeiam as referências dos professores, sejam elas políticas, sociais, religiosas, entre outras. Todavia, 
apontar com clareza os caminhos da pesquisa historiográfica pode evidenciar os pontos nos quais o saber escolar aproxima-se e distancia-se da História acadêmica.

No que concerne ao fazer historiográfico, pode-se dizer que nas últimas décadas viu-se a emergência de uma História Cultural, o que em grande parte se deve a aproximação da História com outras áreas do conhecimento, marcadamente a Antropologia e a Sociologia. A emergência dessa História Cultural está associada ao advento da escola dos Annales, que trouxe em sua essência a crítica a uma História estritamente embasada em personagens / eventos políticos, ampliando os olhares para os estudos do cotidiano, da história das minorias, entre outros, alargando as fronteiras do conhecimento histórico, assim como multiplicando os objetos e problemas de pesquisa.

Sobre esse contexto de influências, Barros (2009, p. 61) elucida,

No século $X X$, os Annales e novos marxismos acionaram um processo de expansão de fontes e objetos de estudo que mais tarde permitirá um resgate maior das relações entre História e relatos produzidos pela Memória. Para captar as pessoas comuns, e não apenas os grandes indivíduos, e também as diversas dimensões da sociedade para além da Política (a Cultura, a Economia, as Mentalidades, etc.) estimula-se uma diversificação de fontes, que nas últimas décadas do século XX (particularmente a partir dos anos 1980) vão atingir também os relatos produzidos por Memórias, o que irá ocasionar o surgimento de um novo setor historiográfico: a História Oral. Essa também é reforçada pela nova ênfase na pessoa comum, nos indivíduos que habitualmente estão excluídos, enquanto singularidades, dos documentos escritos oficiais, dos jornais, das crônicas.

Nessa perspectiva, há o destaque para indícios até então silenciados ou não percebidos pela História tradicional, cujo conceito de verdade histórica se encerrava no documento escrito e na objetividade do historiador. Vê-se então, a construção historiográfica a partir de fontes diversas, tais como, as imagens, a literatura, vestígios variados, os relatos orais. Esse movimento vem acompanhado de um fazer teórico-metodológico da História que procura não naturalizar as fontes, buscando compreender que os documentos, sejam eles iconográficos, orais ou escritos, "(...) não expressam um significado central, 
coerente, comunal, não são transparentes nem inocentes, foram produzidos segundo determinados interesses e estratégias, assim como implicam uma desigualdade na sua apropriação." (STEPHANOU; BASTOS, 2005, p. 419).

Nessa tônica, é possível deixar suspenso o estatuto de verdade dos documentos escritos e abrir espaço para uma História narrada a partir de variadas fontes, nas quais se evidenciam as diversas experiências vividas e as interpelações discursivas individuais e coletivas.

O movimento historiográfico das últimas décadas permite admitir a História como uma ciência interdisciplinar, dado o seu diálogo com outras ciências, que, muitas vezes, auxiliam na compreensão das diversas fontes utilizadas pela historiografia. Guardadas as devidas proporções, o mesmo movimento interdisciplinar é aclamado a estar presente nos Anos Iniciais do Ensino Fundamental. Uma das fases em que o diálogo entre as diversas áreas deveria se dar com mais ênfase, visto a característica de formação do professor atuante, o chamado "polidocente", o pedadogo, ou, em alguns casos, o normalista, que necessita atuar com todas as disciplinas da grade curricular.

Entendendo a História como ciência aberta à interdisciplinaridade e o espaço dos Anos Iniciais do Ensino Fundamental como campo fecundo para o diálogo entre as diversas áreas, é que esse artigo procurar delinear as concepções e práticas que tem se efetivado no ensino de História nessa fase de escolarização.

\section{Ensino de História nos Anos Iniciais, o que dizem as propostas curriculares?}

As propostas curriculares advindas pós década de 1990 trazem como marca o momento de ruptura que se deu nos modos de pensar e ensinar a disciplina. Tal ruptura passa pela renovação das metodologias, de temas e problemas, resultantes dos embates acontecidos na década de 1980, momento em que as discussões acerca das necessárias renovações curriculares se avolumaram nos Estados e municípios, também fomentados pela ampliação dos 
temas e problemas do fazer historiográfico. Essas discussões estavam, então, envoltas no processo de revalorização da História e da Geografia que recebiam de volta, no pós-ditadura militar, o status de áreas específicas do conhecimento. (FONSECA, 2003)

As renovações curriculares do período absorviam ainda as questões colocadas à historiografia no período. Bittencourt (2011) evidencia que enquanto muitos historiadores da década de 1980 aproximaram-se dos sujeitos e objetos de investigação da Antropologia e da Sociologia, à investigação histórica agregavam-se novas fontes como a memória oral, as lendas e mitos, os objetos materiais entre outros. A narrativa histórica, centrada nos fatos, datas e grandes nomes estava às voltas com um processo de renovação que buscava a articulação da macro estrutura com o micro: a História do cotidiano e os diversos sujeitos históricos.

Essa concepção mostrou-se um desafio também para o ensino da disciplina, de modo que as relações entre micro e macro História passaram a fundamentar algumas propostas curriculares posteriores a esse período, entre elas, notadamente, os Parâmetros Curriculares Nacionais (PCN's) para a área, em suas versões para séries iniciais e finais (BRASIL, 1997).

Nesse cenário, viu-se a emergência de propostas curriculares que procuram, de maneira geral, uma fundamentação pedagógica baseada no construtivismo, com abordagens variadas, mas coerentes com o princípio de considerar o aluno um sujeito ativo no processo de aprendizagem. Para tanto, consideram que os alunos trazem consigo um conhecimento prévio sobre os objetos de estudos históricos, seja por meio das histórias de vida ou pelos meios de comunicação, o que deve ser considerado no processo de aprendizagem. (BITTENCOURT, 2011).

Tais propostas apresentam ainda a introdução dos estudos históricos a partir dos Anos Iniciais do Ensino Fundamental, tendo como característica geral a busca por ultrapassar a limitação de uma disciplina aprendida com base nos feitos dos grandes nomes, apresentados em datas cívicas, tal como se dava nos Estudos Sociais, o que tendia ao esvaziamento dos conceitos básicos da disciplina. Sobre esse método Bittencourt (2011, p.76) afirma, 
Os conteúdos organizavam-se por estudos espaciais - do mais próximo ao mais distante -, e os estudos históricos tornavam-se bastante reduzidos, constituindo apêndices de uma Geografia local e de uma Educação Cívica que fornecia informações sobre a administração institucionalizada (municípios, Estados, representantes e processo eleitoral), sobre os símbolos pátrios (hinos e bandeira) e sobre os deveres dos cidadãos: voto, serviço militar, etc.

Pesquisas recentes sobre o ensino da disciplina nos Anos Iniciais indicam a persistência desses conteúdos, a que se refere Bittencourt (2011), nas práticas docentes. Tais estudos analisam esse fator a partir da formação do docente que atua nos Anos Iniciais ou mesmo como uma dita herança da formação nacionalista e patriótica a qual se prestou a História, ao longo da sua constituição como disciplina escolar. (ABUD, 2011; AZEVEDO, 2010)

Nos PCN's há a indicação para organização dos conteúdos em eixos temáticos. Os eixos propostos procuram introduzir noções e conceitos básicos para a História a partir do processo de alfabetização, sendo progressivamente trabalhados ao longo de todo o Ensino Fundamental e Médio. No documento curricular destacam-se os conceitos de cultura, de organização social e do trabalho e as noções de tempo / espaço históricos, sendo que o conceito tempo é apresentado por meio da noção do antes e do depois, buscando uma construção conceitual que não se restrinja a ideia de tempo cronológico (BITTENCOURT, 2011).

Bittencourt (2011) aponta a presença em algumas propostas pedagógicas de uma concepção de história do local ou de "história do lugar" que, de maneira geral, procura estabelecer relações entre o mais próximo, o vivido da criança, e a história nacional, regional e geral ou mundial. A autora ainda complementa,

Os estudos de História têm como base o desenvolvimento intelectual do educando, e daí a recomendação de introduzir o conteúdo a ser estudado por um problema situado no tempo presente, buscando em tempos passados as respostas para as indagações feitas. (BITTENCOURT, 2011, p. 114) 
A essa história local, articula-se a história do cotidiano que, junto a seus métodos, oferece ao ensino da disciplina as ações de pessoas comuns na constituição histórica, colocando homens, mulheres, crianças e idosos na condição de sujeitos da História, tirando o foco das ações exclusivas de políticos e das elites sociais.

O saber histórico escolar, a partir da influência da historiografia contemporânea, objetiva então estabelecer articulações constantes, nos diferentes níveis escolares, entre o local, o nacional e o geral, utilizando, para tanto, as diferentes fontes históricas para a aquisição desse saber.

Delineadas as influências que permeiam a construção dos currículos oficiais para o ensino de História nos Anos Iniciais, importa agora verificar como essas influências materializam-se nas proposições curriculares dos docentes que atuam nessa fase de escolarização, por meio de suas afirmações sobre esse cenário.

\section{Ensinar História nos Anos Iniciais: quais conteúdos, concepções e metodologias?}

Em pesquisa sobre o ensino de História nos Anos Iniciais, Azevedo (2010) indica na memória espontânea de futuras professoras / pedagogas a persistência da História como uma matéria decorativa, centrada em um nacionalismo marcado pela exaltação dos grandes nomes e das datas cívicas. A autora remete este fato às lembranças registradas por esses indivíduos durante o seu processo de escolarização no Ensino Fundamental.

No mesmo sentido, Abud (2012) aponta a persistência nessa visão da História como uma disciplina cuja tradição escolar obriga a decorar, sendo tal tarefa algumas vezes auxiliada pelos feriados nacionais. Segundo a autora,

Tal concepção auxiliou o enraizamento de representações negativas sobre a disciplina e seu ensino e transpôs para o 
imaginário escolar a ideia da sua desimportância e da falta de necessidade de seu ensino. Os professores da primeira fase do ensino fundamental que carregam essa experiência negativa, também a repassam para seus alunos, evitando ao máximo trabalhar, em suas salas de aula, tais conteúdos. (ABUD, 2008, p. 558)

Dessas considerações, destaca-se o necessário investimento em formação inicial e continuada dos profissionais que atuam nos Anos Iniciais, sendo essa função marcada pela polidocência, na qual se exige desse professor o domínio de várias disciplinas, o que tende a tornar frágil o domínio conceitual em determinadas áreas do conhecimento, configurando um dos grandes desafios da formação do docente pedagogo.

Os questionários analisados pela pesquisa "Ensino de História nos Anos Iniciais, conteúdos, métodos e concepções" indicaram um público de docentes que em sua totalidade apresenta curso superior em Pedagogia, destaca-se ainda, que desse público metade concluiu cursos de pós-graduação. O público representado nos questionários permite uma generalização para a Região Metropolitana de Belo Horizonte, onde se têm percebido um avanço no nível de escolaridade do profissional dos Anos Iniciais, espaço preenchido historicamente pelo professor normalista.

Contudo, destaca-se que os docentes submetidos à pesquisa indicam uma concepção de História na qual a disciplina ganha significado na condição de "mestra da vida". Ao serem questionados sobre a importância do ensino de História, os docentes indicam afirmativas vagas, tais como "não se pode conceber o futuro sem antes conhecer sua história", "a história é uma ciência que tenta compreender o passado e o presente da humanidade, entendendo essas relações, é possível construir um futuro melhor", "conhecer o passado para modificar o futuro", etc.

Nessa representação, o conhecimento histórico torna-se importante para o porvir, não sendo agregador para o desenvolvimento do conhecimento no presente. Fator que gera indícios de que a formação superior não foi efetiva quanto à ruptura de uma visão historicamente tradicional da disciplina História, no caso desses docentes. 
Destaca-se ainda, as representações da História relacionadas a uma formação para a cidadania, nas quais os docentes afirmam ser a disciplina importante por: "construir a cidadania, criando condições para que se tornem conscientes e críticos, valorizando a si próprios como sujeitos históricos" ou ainda, "é importante para o exercício pleno da cidadania".

Tais afirmações refletem as indicações dos PCN's ao trazerem como objetivos para o ensino de História a formação para a cidadania. Também vai ao encontro do que afirma Monteiro (2002) ao considerar que a disciplina está imbricada em uma profunda relação com as práticas sociopolíticas e culturais da sociedade, além de ser comum reconhecer nos profissionais dessa disciplina um compromisso afirmado e vivenciado com uma formação para a cidadania.

Fonseca (2003) considera ainda que nas propostas curriculares emergentes após a década de 1980 é recorrente o objetivo expresso para a disciplina, nas quais se verifica a ênfase na preparação dos cidadãos para uma sociedade democrática. Segundo a autora,

Isso é verificável em todos os currículos e materiais didáticos produzidos no período pós-ditadura militar. O "novo" ensino de história que se esboça assume a responsabilidade de formar o "novo" cidadão, capaz de intervir e transformar a realidade brasileira. A categoria "novo" indica a necessidade de superação do "velho", identificado com a ditadura, a opressão, a ausência de liberdades e a negação de direitos. (FONSECA, 2003, p. 92).

Ao considerar a inserção da categoria cidadania relacionada aos objetivos de ensino, nota-se a apropriação nos registros dos docentes das influências que compõem as reformas curriculares e os discursos educacionais.

Fator de destaque em relação ao ensino de História se refere às poucas aulas semanais destinadas à disciplina. Os questionários indicam que a maioria do público consultado ministra de uma a duas aulas por semana apenas, com uma média de uma hora/aula. Os dados do questionário vão ao encontro do que anunciam pesquisas recentes sobre o ensino da disciplina nos Anos Iniciais. Sobre esse tema, Abud (2012, p. 556) afirma, 
A restrição ao tempo para se ensinar a disciplina (História) e a valorização da Língua Portuguesa e da Matemática constituem-se em fatores primordiais para a exclusão das outras matérias. Fato este que implica na dificuldade de aprendizagem das disciplinas privilegiadas, pois as excluídas significam portas abertas para desenvolver importantes capacidades intelectuais de relatar, raciocinar, compreender, narrar, etc, fundamentais para o desenvolvimento da escrita e domínio da língua e do pensamento científico.

No mesmo sentido, Silva (2013) aponta uma desvalorização do saber histórico nos Anos Iniciais, tal fato é atribuído ao foco na alfabetização, de acordo com o que determinam os documentos oficiais para os três primeiros anos de escolarização. O autor corrobora com Silva e Fonseca (2010), que consideram que algumas concepções e práticas de ensino não inserem o conhecimento histórico no processo de alfabetização e letramento, de maneira que a História apenas é introduzida após a consolidação da leitura e da escrita. Entretanto, consideram ainda que,

O "foco na alfabetização", todavia, não pode perder de vista as diversas dimensões que o processo envolve, pois, como nos ensinou Paulo Freire, ler é ler o mundo: não podemos aprender a ler as palavras sem a busca da compreensão do mundo, da História, da Geografia, das experiências humanas, construídas nos diversos tempos e lugares. (SILVA; FONSECA, 2010, p.60)

Os PCN 's reafirmam a necessária inserção do ensino de História, desde os primeiros anos de escolaridade, ao fazer a indicação metodológica,

No caso do primeiro ciclo, considerando-se que as crianças estão no início do processo de alfabetização, deve-se dar preferência aos trabalhos com fontes orais e iconográficas e, a partir delas, desenvolver trabalhos com a linguagem escrita. (BRASIL, 1997, p.49)

Nessa perspectiva, o ensino de História possibilita a leitura de mundo a que se refere Freire, necessária ao desenvolvimento das habilidades inerentes ao letramento. Entende-se, portanto, que o ensino da disciplina possui importantes 
fundamentos que garantem a sua inserção nos primeiros anos do Ensino Fundamental. As indicações dos PCN's corroboram com essa afirmativa, ao propor aos docentes o trabalho com a oralidade e a iconografia, como formas de introduzir a criança na leitura das diversas fontes de informação, objetivando o desenvolvimento paulatino da autonomia intelectual.

Sobre a seleção de conteúdos escolares, Bezerra (2007) considera que eles não são mais um fim em si mesmo, perante um projeto educacional, anunciado pela Lei de Diretrizes e Bases da Educação Nacional (LDBEN), no 9394/1996, no qual,

(...) os objetivos da escola básica, segundo essa lei, não se restringem à assimilação maior ou menor de conteúdos prefixados, mas se comprometem a articular conhecimento, competências e valores, com a finalidade de capacitar os alunos a utilizarem-se das informações para a transformação de sua própria personalidade, assim como para atuar de maneira efetiva na transformação da sociedade. (BEZERRA, 2007, p. 37)

Nessa perspectiva, os conteúdos configuram-se como meios básicos para a construção de competências cognitivas e sociais, sendo que sua escolha e seleção deve considerar o cenário social em cada época. Dessa forma, a construção de um conhecimento histórico escolar significativo desloca o interesse pela quantidade de conteúdos a serem ministrados e suas possíveis lacunas, e passa a colocar em evidência o modo de trabalhar os conceitos históricos, em seus temas, assuntos e objetos.

Na mesma tônica, destaca-se dos PCN's uma organização dos conteúdos por meio de eixos temáticos. Percebe-se a inserção de tais eixos nas seleções de conteúdos apontados pelos professores participantes da pesquisa, visto que quando questionados sobre os dois últimos conteúdos trabalhados em sala de aula, os docentes que atuam nos três primeiros anos de escolaridade, ou primeiro ciclo de acordo com os PCN's, anunciaram ter trabalhado, entre outros, temas como os diversos tipos de moradia, o prédio escolar, direitos e deveres das crianças, documentos pessoais, história da família, brinquedos e brincadeiras antigas. Nos apontamentos dos docentes é notável a simbiose entre os temas 
trabalhados e os conteúdos comumente abordados pelos livros didáticos de História dessa fase de escolarização.

Tais assuntos enquadram-se nas diretrizes dos PCN's, em consonância com o eixo temático "História Local e do Cotidiano", cujo enfoque está nas diferentes histórias relacionadas aos grupos de convívio da criança, dimensionadas em diferentes tempos. Nessa organização de conteúdos, destacase que,

(...) no primeiro ciclo, os alunos iniciem seus estudos históricos no presente, mediante a identificação das diferenças e das semelhanças existentes entre eles, suas famílias e as pessoas que trabalham na escola. Com os dados do presente, a proposta é que desenvolvam estudos do passado, identificando mudanças e permanências nas organizações familiares e educacionais. (BRASIL, 1997, p.52)

De acordo com os questionários aplicados, a influência da chamada "História Local" e da "História do Cotidiano" aparece nos apontamentos dos docentes, que consideraram os conteúdos História local (bairro, cidade) e História pessoal da criança, como os mais importantes de serem trabalhados nos Anos Iniciais do Ensino Fundamental. Todavia, atribuem o mesmo grau de importância entre o trabalho com as "datas cívicas" e a "História e Cultura Afrobrasileira e indígena", apesar de ser esta última temática de inserção obrigatória, de acordo com a Lei 11.645/08.

Em relação ao $4^{\circ}$ e $5^{\circ}$ ano de escolaridade, aparecem com mais força indicações que se aproximam dos conteúdos clássicos da História do Brasil trabalhados nas séries finais do Ensino Fundamental. Os docentes indicaram como dois últimos conteúdos, entre outros,

Datas cívicas;

História e convívio dos indígenas;

Descobrimento do Brasil;

Colonização;

A pré-história em MG;

Os primeiros habitantes e a colonização;

Os índios e a sua cultura;

Grandes navegações; 
História do Brasil;

Período açucareiro e economia na América portuguesa;

Ciclo do ouro;

Descobrimento do Brasil e capitanias hereditárias;

As revoltas coloniais;

A corte portuguesa no Brasil. (Questionários)

A presença destes conteúdos nesses anos de escolarização, em parte, se justifica pelo domínio da leitura e da escrita mais consolidados nessa fase, momento em que permite ao docente explorar com mais afinco os textos históricos escritos. Para essa fase de escolarização, os PCN's indicam que, juntamente com a história oral e a iconografia, sejam trabalhados textos escritos em diversas fontes, livros, jornais, revistas, entre outros. Destaca-se que nos parâmetros curriculares, a concepção alargada de fontes históricas aparece como objetivo para o ensino da disciplina nos Anos Iniciais.

Nota-se ainda que, para o segundo ciclo, ou $4^{\circ}$ e $5^{\circ}$ anos do Ensino Fundamental, os PCN's indicam como eixo temático "História das organizações populacionais", de maneira que, configurando-se como tema genérico, permite a introdução de conteúdos como o "descobrimento" e a colonização no Brasil, a história de Minas Gerais, entre outros.

O referido eixo temático aponta que,

Nessa fase, é importante que os alunos dimensionem as relações sociais, econômicas, políticas e culturais que vivenciam, enriquecendo seu repertório histórico com informações de outras localidades para que possam compreender que seu espaço circundante estabelece diferentes relações locais, regionais, nacionais e mundiais. (BRASIL, 1997, p. 63).

$\mathrm{Na}$ perspectiva de Sacristán (2000), pode-se entender os PCN's na condição de currículo oficial, dado que tal documento propõe-se a orientar os sistemas de ensino em relação a educação obrigatória. Todavia, o mesmo autor tece considerações acerca das limitações de inserção do currículo oficial na esfera da prática, uma vez que considera que os professores são os agentes decisivos na efetivação dos conteúdos e significados dos currículos, visto que moldam as propostas que Ihes são dirigidas de acordo com sua cultura 
profissional, sejam elas vindas da administração dos sistemas, seja do currículo elaborado pelos materiais, guias, livros didáticos, etc.

Nesse sentido, pode-se afirmar que a permanência dos conteúdos ditos tradicionais da História no $4^{\circ}$ e no $5^{\circ}$ ano do Ensino Fundamental é parte de uma "seleção cultural escolar", na perspectiva de Forquin (1992), permeada por uma notável herança dos Estudos Sociais no ensino da disciplina nos Anos Iniciais, endossando uma marca nacionalista e patriótica. A Lei 5.692, de agosto de 1971, instituiu os Estudos Sociais no então chamado Primeiro Grau. Sobre esse método de ensino, Bittencourt (2011, p. 76), afirma,

\begin{abstract}
As datas cívicas e as comemorações dos feitos dos heróis e dos "grandes acontecimentos nacionais" eram, na prática, os únicos "conteúdos históricos" para alunos dessa faixa etária. A comemoração ou rememoração da "descoberta do Brasil, da "independência do Brasil", da "abolição dos escravos" e da "proclamação da República" tornou-se sinônimo de "ensino de História" para as séries iniciais.
\end{abstract}

Das afirmações de Bittencourt, depreende-se que os conteúdos consagrados no ensino da História mantêm-se em destaque nas salas de aula e nos manuais didáticos da disciplina, que são, em parte, responsáveis pela condução do currículo em muitas salas de aula. (BITTENCOURT, 2004). A amplitude de temas e objetos, cuja proposta ganha força junto à Nova História Cultural, corrente historiográfica na qual os PCN's se orientam, mostra-se ainda tímida, frente aos conteúdos já consolidados pelo saber histórico escolar.

Em relação aos materiais didáticos utilizados para trabalhar os conteúdos históricos, dois terços dos docentes que responderam ao questionário apontou o livro didático como material de destaque, percebe-se a simbiose dos conteúdos apontados pela docente, com os que na atualidade aparecem nas coleções referentes aos Anos Iniciais. Sobre essa questão, Bittencourt (2004, p. 72) destaca,

Ao lado dos textos, o livro didático produz uma série de técnicas de aprendizagem: exercícios, questionários, sugestões de trabalho, enfim as tarefas que os alunos devem desempenhar para a apreensão ou, na maior parte das vezes, para a retenção dos 
conteúdos. Assim, os manuais escolares apresentam não apenas os conteúdos das disciplinas, mas como esse conteúdo deve ser ensinado.

Junto ao livro didático, os docentes destacam também a utilização de material didático, textos em geral, reproduzidos pelos docentes. Quando questionados sobre os materiais didáticos que costumam utilizar nas aulas de História, entre outras afirmativas, apontaram: "atividades xerocadas com desenho", "textos e atividades", "atividade em folha", "atividades impressas", "matrizes".

Tais apontamentos permitem inferir que nas proposições pedagógicas cotidianas com o ensino de História nos Anos Iniciais, as atividades que envolvem a leitura de textos e a escrita permanecem consolidadas nas salas de aula. O uso do livro didático divide espaço com as atividades produzidas pelos docentes, em muitos casos, fotocópias de outros livros didáticos. Em relação a esse tipo de atividade, pode-se novamente recorrer a Forquin (1993), ao ponderar sobre uma "cultura da escola", na qual as atividades produzidas pelos docentes dos Anos Iniciais são uma prática histórica consolidada. Certamente o cheiro de álcool dos antigos mimeógrafos, nos quais as atividades eram reproduzidas, faz parte da memória escolar dos docentes contemporâneos.

Deve-se ainda destacar que a terça parte dos docentes que responderam ao questionário apontaram apenas as atividades produzidas por eles como materiais utilizados, não fazendo menção ao livro didático.

Mediante a verificação de uma aula de História centrada nos materiais textuais, deve-se ressaltar a indicação dos PCN's para o trabalho com as diversas fontes Históricas nos Anos Iniciais, apontando o trabalho com fontes orais e iconográficas para os primeiros anos, momento da alfabetização, e complementam para os anos posteriores,

Valorizando os procedimentos que tiveram início no primeiro ciclo, a preocupação de ensino e aprendizagem no segundo ciclo envolve um trabalho mais específico com leitura de obras com conteúdos históricos, como reportagens de jornais, mitos e lendas, textos de livros didáticos, documentários em vídeos, telejornais. (...) Nesse sentido, cabe ao professor criar situações instigantes que os 
alunos comparem as informações contidas em diferentes fontes bibliográficas e documentais, expressem as suas próprias compreensões e opiniões sobre os assuntos e investiguem outras possibilidades de explicação para os acontecimentos estudados. (BRASIL, 1997, p.61).

E de maneira geral, os PCN's afirmam, "(...) o trabalho pedagógico requer estudo de novos materiais (relatos orais, imagens, objetos, danças, músicas, narrativas), que devem se transformar em instrumentos de construção do saber histórico escolar." (BRASIL, 1997, p. 39).

As indicações dos PCN's mostram-se, todavia, sem uma inserção consolidada nas salas de aula dos Anos Iniciais. As respostas dos docentes aos questionários evidenciam que a iconografia, as músicas e os filmes estão entre os materiais pedagógicos considerados de menor importância. Mesmo entre os docentes que atuam nos dois primeiros anos, momento em que a alfabetização pode não estar plenamente alcançada, o uso das imagens não aparece como alternativa didática para o ensino da disciplina.

No entanto, os trabalhos de campo - sejam eles, visitas a cidades históricas, museus, excursões pelo bairro, entre outras - aparecem como prática pedagógica apontada pelos docentes como importante para o ensino de História. Os limites da pesquisa não permitem esclarecer se estes trabalhos propõem-se de fato a consolidação do saber histórico, ou resumem-se a práticas de visitação.

O uso de variadas fontes, já consolidado na pesquisa histórica, mostra-se como importante para o ensino da disciplina, na medida em que,

Ao se recuperar esses materiais, que são fontes potenciais para construção de uma história local parcialmente desconhecida, desvalorizada, esquecida ou omitida, o saber histórico escolar desempenha outro papel na vida local, sem significar que se pretende fazer do aluno um "pequeno historiador" capaz de escrever monografias, mas um observador atento das realidades do seu entorno, capaz de estabelecer relações, comparações e relativizando sua atuação no tempo e espaço. (BRASIL, 1997, p. 39) 
Outra indicação que permeia as orientações curriculares para o ensino de História está na recorrência da defesa do trabalho interdisciplinar. Nas respostas aos questionários, a grande maioria dos docentes afirmou trabalhar a disciplina em associação com outras, sendo o Português e a Geografia as mais indicadas. Nota-se a manutenção de uma representação clássica da disciplina: ao associála, de imediato ao desenvolvimento das habilidades de leitura e escrita; ao associá-la ao saber geográfico, o que possibilita a compreensão das dimensões temporais e espaciais, mas que também se mostra como uma continuidade da forma de entender a disciplina sob o viés dos Estudos Sociais.

Os aspectos incongruentes entre o previsto nas propostas curriculares e o que se realiza na esfera da prática demonstra os limites dos avanços historiográficos no ensino de História dos Anos Iniciais. Sendo a necessária redução dessa distância, entre o previsto e o praticado, um dos desafios, não recente, posto à disciplina nessa fase de escolaridade.

\section{Considerações finais}

O ensino de História nos Anos Iniciais do Ensino Fundamental mostra-se desafiador no atual cenário educacional: avanços metodológicos e historiográficos no saber de referência; docentes não historiadores; público infantil, com as especificidades do ser criança; inúmeras dificuldades pedagógicas e estruturais que constituem a realidade das escolas nacionais. Entre os elementos apontados por esse artigo, destacam-se algumas mudanças e permanências que endossam os desafios citados.

Em relação a pesquisa "Ensino de História nos Anos Iniciais, conteúdos, métodos e concepções", a totalidade dos docentes participantes indica a conclusão do curso superior, sendo que parcela significativa desses profissionais indica ainda a realização de cursos de pós-graduação. Evidencia-se, portanto, um dado positivo no que se refere à profissionalização do docente que atua nos Anos Iniciais, fase historicamente marcada pela presença das professoras normalistas. Entretanto, não se pode relacionar o aumento da escolarização dos profissionais 
a mudanças significativas na forma de pensar e ensinar a História nessa fase, cuja herança dos Estudos Sociais ainda se mostra presente.

Uma das permanências que mais se evidencia é a manutenção de uma disciplina centrada nos processos de leitura e escrita. O texto permanece como o principal material didático utilizado em sala, quando não, o único. Todavia, se o uso exclusivo do livro didático de História é motivo de críticas (BITTENCOURT, 2004, 2011), a afirmação de que um terço dos docentes que responderam ao questionário não o utiliza pode ser considerado motivo de preocupação, visto que o livro didático exerce nos Anos Iniciais uma função intrínseca, a materialização do saber histórico acadêmico, sendo esse material, em muitos casos, o que liga esse docente, envolvido com as diversas disciplinas, ao saber de referência.

A ampliação de fontes históricas mostra-se ainda com tímida inserção no espaço da sala de aula, fator que, entre outros, demonstra a limitação dos avanços historiográficos no ensino da disciplina para crianças. Músicas, imagens, objetos, relatos orais e tantas outras fontes, passíveis de serem utilizadas como material didático e com potencial para aproximar-se do universo lúdico da faixa etária, são ainda desmerecidos perante o trabalho com a leitura e a escrita. A necessária complementação entre os diversos materiais, na busca pela consolidação do saber histórico escolar, aparece como um desafio posto em grande parte das classes escolares.

Miguel Arroyo (2000) ao falar da educação endossa a ansiedade por novas práticas, métodos e concepções. Todavia, o contato com o cotidiano de muitas salas de aula mostra que suas estruturas curriculares ainda não concebem de fato essa ansiedade, visto que possuem os mesmos programas, quando os possuem, e a mesma forma de lidar com o educando.

Por esse viés, não se pode pensar nas relações de ensino sem fazer as necessárias considerações sobre as relações que se dão na sociedade, a tradicional oralidade da disciplina História, centrada no professor, de lousa e giz - ou o contemporâneo pincel - concorre com uma diversidade de mídias e com avanços tecnológicos cada vez mais acelerados. Sobre esse cenário, Bittencourt (2004, p.14) considera, 
Se esse perfil diferenciado do público escolar tem apresentado desafios para educadores, no caso da História as questões se avolumaram à medida que a sociedade consumista tem se estruturado sob a égide do mundo tecnológico, responsável por ritmos de mudanças aceleradas, fazendo com que tudo rapidamente se transforme em passado, não um passado saudosista ou como memória individual ou coletiva mas, simplesmente, um passado ultrapassado. Trata-se de gerações que vivem o presenteísmo de forma intensa, sem perceber liames com o passado e que possuem vagas perspectivas em relação ao futuro pelas necessidades impostas pela sociedade de consumo que transforma tudo, incluindo o saber escolar em mercadoria.

Percebe-se, todavia, que essas crianças que vivem sob a égide do mundo tecnológico, não mais se surpreendem com tais avanços, nasceram em uma época na qual as inovações são esperadas e alcançam a categoria do normal e do corriqueiro na vida cotidiana, o game de última geração em breve tem que estar ultrapassado para dar espaço a outro com funções aprimoradas. Para essas crianças, parece possível dizer que o surpreendente é o passado, com suas máquinas manuais e seu tempo lento. Os brinquedos e brincadeiras antigas, o dia-a-dia dos antepassados, as fotografias que utilizavam filmes e requeriam uma "pose" pomposa, as canções no disco de vinil, e tantas outras coisas resgatadas de um passado, não muito distante, tornam-se oportunidades de a História despertar a surpresa em tais crianças. Aos professores, um lembrete aparentemente simples: a História é múltipla, assim como as fontes históricas que nos permitem revisitar o passado.

Para essa mesma geração de crianças, cujas possibilidades de entender o mundo mostram-se amplas, o estudo do passado pelo passado, centrado apenas nos textos e atividades de repetição, mostra-se um contrassenso. Este responsável por uma disciplina sempre às vias de responder a questão: História para quê?

\section{Referências}

ABUD, K. M. O ensino de História nos anos iniciais: como se pensa, como se faz. Antíteses. v. 5, n. 10, p. 555-565, jul./dez. 2012. Disponível em: 
http://www.uel.br/revistas/uel/index.php/antiteses/article/view/14505. Acesso em 15 de janeiro de 2014.

AZEVEDO, P. B. O Desafio do ensino de História nos anos iniciais: a questão do nacionalismo. Atos de Pesquisa em Educação. v. 5, n. 3, p. 338-355, set./dez. 2010. Disponível em:

http://www.ufrrj.br/graduacao/prodocencia/publicacoes/pesquisa-praticaeducacional/artigos/artigo5.pdf. Acesso em 15 de janeiro de 2014.

BARROS, J. D'A. História e memória: uma relação na confluência entre tempo e espaço. Mouseion, vol. 3, n.5, Jan-Jul/2009. Disponível em http://revistas.unilasalle.edu.br/documentos/Mouseion/Vol5/historia_memoria.p df. Acesso em 13 de março de 2015.

BEZERRA, H. G. Ensino de História: conteúdos e conceitos básicos. In.: KARNAL, L. (Org.). História na sala de aula, conceitos, práticas e propostas. 5 ed. São Paulo: Contexto, 2007.

BITTENCOURT, C. M. F. Ensino de História: fundamentos e métodos. 4 ed. São Paulo: Cortez, 2011.

BITTENCOURT, C. (Org.). O saber histórico na sala de aula. São Paulo: Contexto, 2004.

BRASIL. Secretaria de Educação Fundamental. Parâmetros curriculares nacionais: História e Geografia. Brasília: MEC/SEF, 1997.

CODANI, N. L. O ensino de história nos anos iniciais: orientações curriculares e concepções de professoras. Dissertação de Mestrado. São Paulo: PUC/SP, 2000.

FONSECA, S. G. Didática e prática de ensino de História: experiências, reflexões e aprendizados. Campinas: Papirus, 2003.

FORQUIN, J. C. Escola e Cultura: as bases sociais e epistemológicas do conhecimento escolar. Porto Alegre: Artes Médicas, 1993.

. Saberes escolares, imperativos didáticos e dinâmicas sociais. Teoria e Educação, Porto Alegre, n.5, p. 28-49, 1992.

MONTEIRO, A. M. da C. Ensino de História: Entre Saberes e Práticas. 2002. Tese (Doutorado em Educação) - Departamento de Educação, Pontifícia Universidade Católica, Rio de Janeiro.

SACRISTÁN, J. G. O Currículo: uma reflexão sobre a prática. 3 ed. Porto Alegre: Artmed, 2000. 
SILVA, E. R. L. da. Materiais didáticos e as múltiplas linguagens no ensino de História dos anos iniciais. Anais XXVII Simpósio Nacional de História. 2014. Disponível em:

http://www.snh2013.anpuh.org/resources/anais/27/1371147152_ARQUIVO_TEX TOANPUH2013MateriaisdidaticoseasmultiplaslinguagensnoensinodeHistoriadosan osiniciais.pdf. Acesso em 15 de janeiro de 2014.

SILVA, M. A. da; FONSECA, S. G. Ensino de história hoje: errâncias, conquistas e perdas. Revista Brasileira de História. São Paulo, vol. 31, n. 60, p. 13-33, 2010.

STEPHANOU, M.; BASTOS, M. H. C. História, memória e história da educação. In: STEPHANOU, Maria; BASTOS, M. H. C. (Org.). História e memórias da Educação no Brasil. Vol. III - século XX. Petrópolis (RJ): Vozes, 2005.

Recebido em 09 de março de 2016 Aprovado em 14 de julho de 2016 